\title{
The Necessity to Encourage Entrepreneurship Students
}

\author{
Sun Guangdong, Gao Bing \\ (Jilin Jianzhu University,Changchun,130118) \\ Changchun city,Jilin province, China \\ Jilin Jianzhu University \\ School of civil engineering, Student \\ 825351735@qq.com;444034176@qq.com
}

\begin{abstract}
International Entrepreneurship, is not what happens, China also actively solve business problems of college students. For this problem, college students should clear business purpose, andgive full play to their own advantages, strive to solve the problem in the process of entrepreneurship.Make a contribution to innovation and entrepreneurship education in China.
\end{abstract}

Key words-College students; Entrepreneurial; Purpose; Problems

- College Students' Entrepreneurship Policy "on
paper"

In recent years,the employment situation of college students is not optimistic, leading students are worried for their future.And on this issue, the Ministry of education allows college students' entrepreneurship policy "paper of formal school". The national Ministry of education notice: promoting innovation and entrepreneurship education and entrepreneurial work, various universities must put the innovation and entrepreneurship education as an important starting point to promote the comprehensive reform of higher education, the innovation and entrepreneurship education throughout the entire process of personnel training for all students, the development of open innovation and entrepreneurship education specialized courses, into credit management, improve teaching methods, strengthen practical effect. On the combination of theory and practice, organize students to participate in all kinds of innovative entrepreneurship competition, entrepreneurship simulation practice,and focus on cultivating students' innovative spirit, entrepreneurial consciousness and innovation ability. Colleges and universities should establish flexible educational system, allowing students drop out of business. Colleges and universities to hire successful entrepreneurs, investors, entrepreneurs, experts and scholars as a part-time tutor, a guide for innovation and entrepreneurship students.

"In 2015 the overall employment situation of college graduates are facing multiple pressures, further increase the scale of employment work, the task is very arduous". In today's society, the employment situation is so difficult, encourage college students entrepreneurship policy officially "on paper", can be said to open another door for college students. However, for the students countries opened a door to the future is good or bad?

- The international situation of College Students' Entrepreneurship

For a country since ancient times, what is the most important -- talent, thus many countries established the plan of talent training, which is a problem of education on College Students' Entrepreneurship on the agenda, how to cultivate students' awareness of entrepreneurship and entrepreneurial enthusiasm, become the world first to solve the problem. On the one hand it can be said, over the years American are ahead of our country, but in the face of this problem we can to draw them to what? Let us analyze the current situation of the development of USA entrepreneurial environment of College students.

[1] In USA, students and success is often seen. From the height of philosophy, success or failure of any career, depends on the career of subjective and objective conditions. Here the so-called subjective condition refers to people's ideas and their own quality and other factors, the objective conditions here refers to the economic system, including policy environment and cultural atmosphere and other factors.

From the subjective conditions, USA students mainly have the following characteristic: the deep content of American values was the American individualism, the personal value and personal honor concept emphasizes the equality of personal struggle, equal opportunity; Open education system stresses individuality ability, pay attention to self-family education, and the freedom of choosing employment mechanism, cultivate good habits America students hands-on ability. From the objective conditions, there are also many social USA is conducive to personal business conditions. For example: encourage individual entrepreneurial social atmosphere; the development of knowledge economy, is conducive to individual entrepreneurship; The entrepreneurship of college students is very convenient; flexible employment mechanism of talent flow; risk of investment funds and the GEM market strong and mature; small and medium-sized the status of enterprises in America.

- The benefits and advantages of the entrepreneurship of College Students

- To solve the employment problem of their own

[2] Our traditional employment channels mainly concentrated in the organs and state-owned large and 
medium-sized enterprises. In the industrial structure adjustment, government agencies, public institutions, to streamline the compilation of finite capacity, not too many college graduates. The reform of many enterprises, a large number of surplus labor will be transferred to the society at the same time could not provide enough jobs to college students. Secondly, China's current between urban and rural areas between the East and the west, the imbalance of economic development, the productivity of western regions and the vast rural areas lagging behind. To provide the working living environment and the level of treatment is relatively low. Most college graduates prefer to stay in the big city "work part-time" rather than to work in remote places "work".

The employment situation is so grim moment, College students hope to find related with their professional work has been very difficult, they can only "compromise", sometimes even their own choice and professional irrelevant occupation. Life is not the lack of opportunity, but the lack of courage to create opportunities, create their own careers with their own hands, so can solve their employment problems, and now the country has for college students' entrepreneurship has issued a series of preferential policies, we can use this point, give full play to the advantages of college students. Policies can be said to be fully encourage students to entrepreneurship, even allow students drop out of business. This is not the country to encourage students not to go to school, but to encourage students to pay attention to the spirit of innovation. Only the courage to venture, university students are not affected by the severe employment situation, lay the foundation for their own development path.

\section{Training college students mental capacity}

The pursuit of entrepreneurship is just to solve their employment problems? Of course not.Even if the employment situation is not optimistic, college students want to have a stable job and not too difficult. In fact, everyone knows what the pursuit of their own is. Rome was not built in a day, entrepreneurship is a long process of exploration, is a time for college students' psychological endurance training opportunities. What is the purpose of College Students' Entrepreneurship? In fact,for our dedication in the study, we don't need to give us a satisfactory answer? Everyone has a steelyard, to measure the gain and lose for themselves. College students should be fully able to understand what you want. Make your university life has a perfect ending, no regrets. Faith in the dream through their own hands to gain. So the heart will burgeon a sense of achievement, this can be said that causes the success you desire, do not want to fail, But it needs to have good compressive ability, otherwise it will fall into the life of failure, even you will feel life is meaningless. [3] In real life, students must learn to properly set goals according to their actual ability of self-adjustment, Experiencing pleasure and satisfaction. In success, and gradually improve self-confidence. Secondly, understand and evaluate themselves correctly. Enhance the cognitive ability for failure, failure is a part of society, is the inevitable experience of life, college students should correctly understand the failure. Challenge can change the unfavorable factors into favorable factors, let the failure to transform to the positive side, take the failure as the ladder of success, and build psychological defense mechanism.

\section{- A new vitality for social perfusion}

When we satisfy the "desire". At the same time, college students' entrepreneurship pour new vitality into the society. At least now entrepreneurship has not really formed the moment, their business as Pathfinder, can be said to have both the advantages and risks. College students' mind is active. Although the social experience is insufficient. The college students a lot of time and not in learning, but in the "growth". Of course, this is not to say the growth of age, the most important thing in life is the transition from adolescence to maturity while the undergraduate curriculum. University curriculum should be much easier than high school course, which makes plenty of spare time can be used. So that students have more practice to learn through the Internet, books, can be said that if the students' entrepreneurial success, they in the field of management thinking will be a big change from the traditional management mode, it can be said to be a thinking innovation is no longer follow the traditional pattern. In general, people's curiosity is very strong. A novel thing will make them feel curious, but this is also your business opportunity, or even can be said that you drive the development of the whole industry. Also, this result can attract more attention on college students' entrepreneurship. It can be said to meet their own at the same time also inspire others, according to the national policy, successful entrepreneurs should act as a mentor for other students' role, the exchange of experience can let students understand entrepreneurship in all. The lack of experience is college students' common problem. At the same time, the exchange of experience is a kind of power, let more students' life rich and colorful. More and more people start a business, which makes the job demand bigger. It can be said is for the employment of university students and solve many problems. In addition, many people have serious herd heart, also known as the "follow the trend of psychological", so you experience can be said to bring them into the business door to the key, this is undoubtedly to promote the progress of the society. More and more people start to solve the problem. Help others also help yourself.

\section{- Independent entrepreneurs will face problems \\ - College students lack of social experience}

This is the so-called "to do good work must first sharpen his tools", we don't have enough capital in time, will not venture out, otherwise it may fail. Entrepreneurship is actually a knowledge, if no major knowledge base, rich imagination, and social experience enough, it is difficult for us to have a business of their own in the society. We are not lack of theoretical knowledge. As a college student, nothing 
can limit our thinking, college students' idea is a powerful and unconstrained style. So that the problem of entrepreneurship students is lack of social experience.

Directly after graduation entrepreneurship is not "good or bad", but "should or not" problem, no experience is no way to gain a foothold in society, and the practice is the best way to learn, the most simple way is our experience, if we strengthened the heart of entrepreneurship, then we must go to this goal you don't try their own shortcomings, as long as willing to pay, there will be a return, so, we must first start from the grassroots, no one can attain the highest level in one step should learn from the experience in practice, from the mistakes, understand deficiencies, develop their own in the improvement, improve their own entrepreneurial path, so there are a lot of people not willing to "start from scratch". This is why the topic of College Students' Entrepreneurship was left out.

\section{The school lacks execution of policy}

From external factors, though countries have to encourage students to entrepreneurship action. However, Not every university all has a good propaganda way

- School do not pay attention to college students' entrepreneurship, it leads to some ill-informed students, did not understand the national attention for the entrepreneurship of College students. For this phenomenon, the school should be considered for the future of students, for students to hire some successful entrepreneurs or entrepreneurial professionals to set up a forum for college students. Explain entrepreneurial knowledge, after all the students for systematic learning is easy to accept. And college students' understanding ability is good. Many students will go out to do a part-time job in their spare time, but also have some social experience, combined with professional guidance, it would be easy to find their own direction and method. Therefore, the school play a vital role in college students' entrepreneurship. [4] The schools should offer entrepreneurship education courses. There are plans to carry out entrepreneurship education. To cultivate the knowledge structure and quality of college students is reasonable. And entrepreneurship education can help college graduates to create more jobs, promote more employment. The school should also carry out entrepreneurship education, cultivate entrepreneurship awareness, pay attention to business practice activities, adhere to reform and innovation, focus on the cultivation of students' entrepreneurial ability, will focus on to "create", rather than "career", and strengthen the construction of entrepreneurship education teachers. The school should first solve the problem of adequate entrepreneurship preparation manufacturing for college students.

\section{- Don't agree with their parents}

The contradiction of a large part of college students from the family. [5] In the investigation of cognition and entrepreneurship support policies of college students parents of students. $27.4 \%$ of parents said they did not understand, $40.5 \%$ of parents said they only know a little bit.
$19.3 \%$ of parents said they learn a lot. $12.8 \%$ of parents said they are very understand; In the investigation of the parents of students' entrepreneurial behavior attitudes, $52.3 \%$ of parents said they do not support, $36.5 \%$ of parents said "if the children insist on business, we can accept, $11.2 \%$ of parents expressed their full support, including on entrepreneurial behavior and helping policy" did not understand "parents were all chose not to support; even on Entrepreneurial behavior and helping policy" very understanding "of the parents, to fully support the entrepreneurial is also several $75.68 \%$.Because of the different age of living, the education is not the same. Current college students' parents' education level is not very high. So they hope their children to study well, but now the college students are no longer as it was before. In the past, the every college students can be called God's favored one. Now students to everywhere. How to make yourself stand out from a number of college students, show their distinctive talent. It is necessary to have the courage to fight and practice. Don't be affected elders' old ideas .And o enrich themselves through practice, only in this way can you find the flash point, and then seize the opportunity, you will give full play to their talents. Since the country maintained a positive and cooperative attitude for students. Then students have the courage to seize the opportunity, and usually communicate with their parents, learn about the entrepreneurial advantages and disadvantages, mutual understanding, common development, if have the support of parents will developfurther in the entrepreneurial. This is equal to you a step closer to success.

\section{- Conclusion}

Anxious to achieve quick success is the characteristics of college students, not through the baptism of the community is difficult to become stable, but this is precisely the advantage of student entrepreneurship, need to meet the conditions what? The first to have patience, sometime, college students have lack of social experience, therefore do not be anxious for success too, have enough patience for in the grass-roots community, after taking to the familiar, to make further plans. Then is the need to have entrepreneurial mind, sometimes need to be good at thinking, and not by a weigh the advantages and disadvantages, passion can be successful, blind imitation of others can't be regarded as the experience, can only be regarded as plagiarism, we want to have their own ideas, thinking and thinking is amazing, observe the undergraduate years learning honed instinct, can be said to be the basic advantage the entrepreneurship of College students. Wait until after learning some experience, then you need to consider the situation of the overall view, to consider their own situation, hobbies according to their professional knowledge and interest, positioning their own entrepreneurial direction, and formulated a series of development plans, to find a suitable opportunity to develop. The last but the most important is the courage, "entrepreneurship" is mainly an "innovation", innovation is a difficult road, every new growth must be 
accompanied by a variety of risk and resistance, but can persist is the key to success. Entrepreneurs need courage firm down, In the face of difficulties do not retreat. When the courage to overcome difficulties you are not far from success

Thanks to the Jilin Jianzhu University support for the project and sponsorship.This paper by the Jilin Jianzhu University students' innovation and entrepreneurship training project funding.Project number:201310191015.

\section{REFERENCES}

[1] Zhang Fan.The comparative analysis of the college students' entrepreneurial environment.Scientific Management Research

,2010,28(1)

[2] Bai Yuxin.Status and countermeasures of college students' employment.Legal and Economic, April,2010

[3] Zhang Li.Analysis of college students' entrepreneurship psychological change trend.Technological Development of Enterprise, February, 2013, 6(32)

[4] Peng Feng .Think of entrepreneurship education for college students in colleges and universities.Journal of Huaibei Professional and Technical College, June, 2010, 3(9)

[5] Liu Guilai, Cui Xiaopei.The influence of family factors on college students' self-employment.Journal of Hebei University of Economy and Business (Comprehensive Edition), March, 2013, 1(13) 